\title{
Journal of Biomaterials
}

\section{Features of High Current Nanosecond Discharge in Mixture of High Pressure CulnSe ${ }_{2}$ Chalkopyrite Vapor and Argon}

\author{
Shuiabov Oleksander ${ }^{1}$, Mynya Oleksander ${ }^{1}$, Chyhin Vasyl $^{2}$, Grytsak Roksolana $^{1}$, \\ Malinina Antonina ${ }^{1}$ \\ ${ }^{1}$ State Higher Educational Institution "Uzhhorod National University", Uzhhorod, Ukraine \\ ${ }^{2}$ National Land Forces Academy, Lviv, Ukraine
}

Email address:

alexsander.shuaibov@uzhnu.edu.ua (S. Oleksander)

\section{To cite this article:}

Shuiabov Oleksander, Mynya Oleksander, Chyhin Vasyl, Grytsak Roksolana, Malinina Antonina. Features of High Current Nanosecond Discharge in Mixture of High Pressure CuInSe 2 Chalkopyrite Vapor and Argon. Journal of Biomaterials. Vol. 3, No. 2, 2019 , pp. $37-41$. doi: $10.11648 /$ j.jb.20190302.11

Received: August 5, 2019; Accepted: November 20, 2019; Published: December 17, 2019

\begin{abstract}
The features of an over-voltage high-current nanosecond discharge in argon of high pressure $(\mathrm{p}=202 \mathrm{kPa})$ ignited between the electrodes of $\mathrm{CuInSe}_{2}$ compound are presented. In the sputtering of massive chalcopyrite electrodes, the CuInSe pair gets into the discharge plasma. Main products of dissociation of chalcopyrite molecules in the over-voltage nanosecond discharge are established. They were in excited and ionized states and in the spectra of plasma radiation they were predominantly represented by atoms and single charged ions of copper and indium. It is proposed to use the spectral lines of copper and indium to control the process of thin films of chalcopyrite deposition in a real time. Using gas-discharge method thin films of chalcopyrite are synthesized on quartz substrates. These films effectively absorb the radiation falling on their surface in the spectral range of 200-800 $\mathrm{nm}$. This property opens the prospects for their application in photovoltaic devices
\end{abstract}

Keywords: Chalcopyrite Electrodes, Over-voltage High-Current Discharge, Excited and Ionized States, Thin Films

\section{Introduction}

At present, chalcopyrites of $\mathrm{CuInSe}_{2}$ type are promising materials for use in solar panels. This is due to high coefficients of an solar radiation absorption by these materials and their high light stability. In papers $[1,2]$ results of investigations of characteristics and parameters of the laser erosion plasma formed from the corresponding polycrystal target $\left(\mathrm{CuInSe}_{2}\right)$ in a vacuum are reported. Laser spraying allows to receive high-quality thin chalcopyrite films of the stoichiometric composition. However, in this case the output of materials for solar energy is low, and the process of synthesis of such films is too costly. Therefore, at present, the development of other physical methods for the synthesis of thin chalcopyrite films suitable for using in photovoltaic converters, remains relevant.

It may also be promising to use over-voltage nanosecond discharges in gases to sputtering of massive chalcopyrite and metal electrodes [3, 4]. At work in air of atmospheric pressure the necessity of application of cost vacuum and laser equipment is eliminated. Due to the generation under some conditions in these discharges of beams of "escaping electrons" and associated X-rays, they are sufficiently homogeneous and suitable for deposition of thin nanostructured films on various substrates.

Currently the most studied are subnanosecond highvoltage discharges in air and nitrogen, which are ignited between metal electrodes at a distance between them in the range of $1-15 \mathrm{~cm}[5,6]$. Discharges of nanosecond duration between polycrystalline semiconductors at inter-electrode distances in the range of $1-5 \mathrm{~mm}$ are less studied.

This paper presents the results of a research of features of the over-voltage nanosecond discharge in high pressure Ar$\mathrm{CuInSe}_{2}$ vapor-gas mixtures with injection of chalcopyritebased electrode vapors into gas medium due to their sputtering during the formation of ectons.

\section{Experiment Conditions}

The nanosecond discharge between chalcopyrite electrodes $\left.(\mathrm{CuInSe})_{2}\right)$ was ignited in the sealed discharge chamber 
(Figure 1). The distance between the cylindrical electrodes of chalcopyrite with a diameter of $5 \mathrm{~mm}$ was $1 \mathrm{~mm}$. The radius of curvature of the working end surface of chalcopyrite electrodes was the same and was of $3 \mathrm{~mm}$.

The discharge chamber with the electrode system was evacuated by the low-vacuum pump to the residual air pressure of 5-10 $\mathrm{Pa}$. The working pressure of high purity argon in the chamber was of $202 \mathrm{kPa}$.

The ignition of discharge was performed using the highvoltage modulator of bipolar voltage pulses with a total duration of 50-150 ns. The amplitudes of the positive and negative components of the high-voltage pulse were in the range of $10-40 \mathrm{kV}$. The repetition frequency of the pulse voltage in the experiments was of $100 \mathrm{~Hz}$. Ostsillograms of voltage pulses at the discharge gap and current waveforms of pulses were registered using the wide-band capacitor divider, the Rogowski coil, and the wide-wave oscilloscope 6-LOR04 . The temporal resolution of the measurement of electrical pulse characteristics was of 2-3 ns. To record plasma emission spectra it was used the MDR-2 monochromator and the photomultiplier FEU-106. The signal from the photomultiplier was fed to the amplifier and was recorded using the amplitude-to-digital converter in the automated spectrum measurement system with the personal computer display. The discharge radiation was analyzed in the spectral range of 200-650 $\mathrm{nm}$. The experimental technique is given in [6] more detailed.

The quartz substrate was installed at a distance of $3 \mathrm{~cm}$ from the center of the discharge gap (Figure 1). The discharge burning time was set of about 3 hours. Then, the gray film deposition was observed on the substrate. This film consisted of sputtering products of electrodes based on the CuInSe2 compound. Method of investigation of the absorption spectra of films is presented in [10].

\section{Characteristics of Discharge}

In the system of chalcopyrite electrodes at the gas pressure $\mathrm{p}\left(\mathrm{N}_{2}\right)$ and $\mathrm{p}(\mathrm{Ar})=200 \mathrm{kPa}$ and at the distance between the electrodes $\mathrm{d}=1 \mathrm{~mm}$ the spatially homogeneous discharge in the form of a sphere was ignited. This discharge was formed without an use of the separate system of pre-ionization of the interelectrode gap. The role of the pre-ionization system here can be played by an beam of "runaway" electrons or x-ray of electrons [8].

At the low gas pressure $\mathrm{p}=1-10 \mathrm{kPa}$ in the plasma a threshold of transfer of a large part of electrons to the continuous acceleration mode can be reached [9]. But at the atmospheric pressure of gases the efficiency of electron escape decreases sharply, so the main is the pre-ionization by $\mathrm{X}$-ray radiation.

Typical dependences of the electric pulse power of the nanosecond discharge in argon are presented in Figure 2. The pulse power was obtained by graphically multiplying the oscillogramm voltage across the gap and the discharge current. In the experiment, oscillations of the voltage at the discharge gap with a half-period close to 10 ns were recorded. These oscillations are caused by a non-compliance of the output impedance of the high voltage pulse modulator with the load resistance. Current pulses of the over-voltage nanosecond discharge had the appearance of damping oscillations with amplitudes up to $150 \mathrm{~A}$.

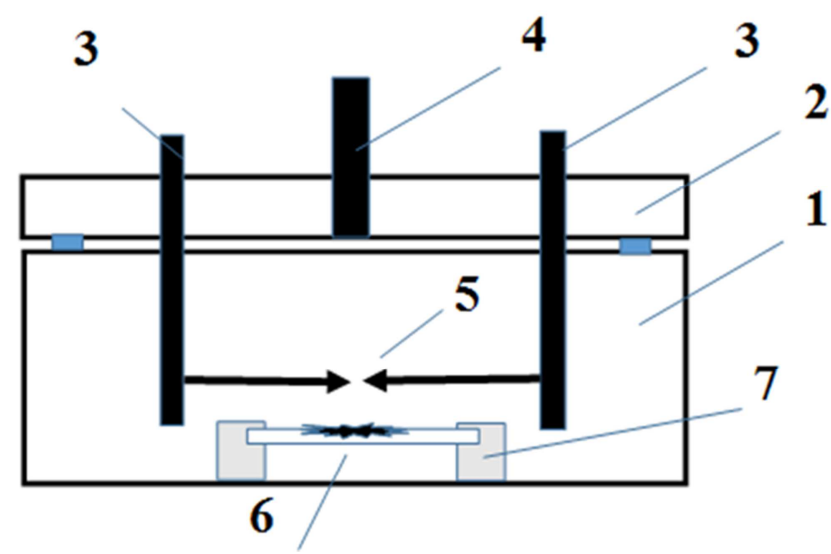

Figure 1. Scheme of the discharge device for the synthesis of thin chalcopyrite films on the glass surface: 1 - gas-discharge chamber of plexiglas, 2 - upper flange, 3 - sealed metal inputs, 4 - fitting for connection to the vacuum gas-mixing system, 5 -chalcopyrite electrodes, 6 - quartz film substrate based on scattered chalcopyrite electrodes, 7 - the plate mounting system.

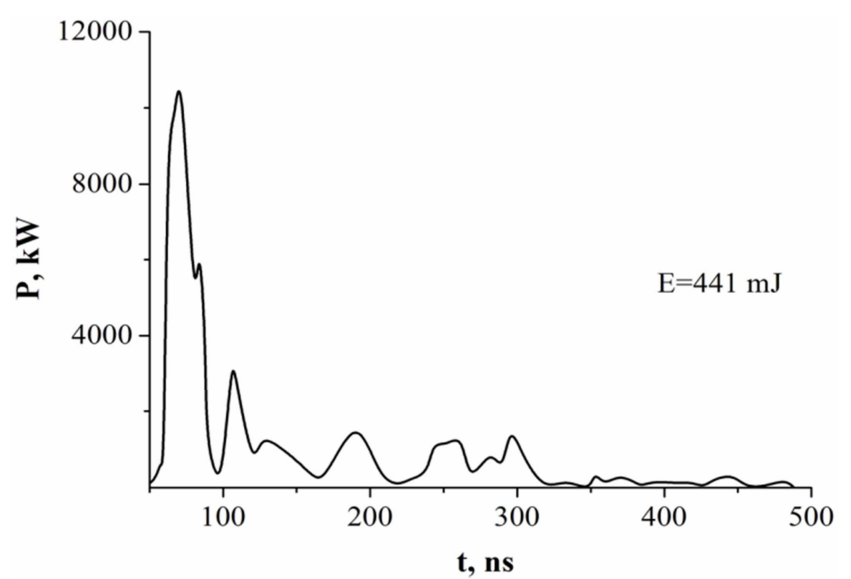

Figure 2. Pulse power of over-voltage nanosecond discharge at $p(A r)=202$ $k P a$.

The main part of the electrical pulse power was introduced into the plasma of the over-voltage nanosecond discharge in the first 100-150 ns. Maximal electric pulse discharge power in both vapor-gas mixtures was achieved at $p(A r)=202 \mathrm{kPa}$ and was of 10.5 MW. When the pressure of gas environment was reduced to $1 \mathrm{kPa}$ the pulse power was reduced to $7 \mathrm{MW}$.

The graphic integration of the pulse power over time allowed to calculate the energy of one discharge pulse introduced into the plasma. So, the energy contribution to the plasma for argon-based vapor mixtures at $\mathrm{p}(\mathrm{Ar})=202 \mathrm{kPa}$ reached $440 \mathrm{~mJ}$ [10].

The linear part of the radiation spectrum was observed against the background of continuous radiation (continuum) of plasma. This may be due to the thermal radiation of the plasma or its recombination radiation. As it is shown in [11], 
copper and indium atoms are the least bound in the chalcopyrite molecule, which is a constituent of massive electrodes. Therefore, the linear part of the plasma emission spectrum is predominantly due to separate spectral lines of atoms and singly charged copper and indium ions. This was observed both for the laser plasma formed on the surface of the compound target under vacuum conditions $[12,13]$ and for the gas-discharge plasma [14].

Figure 3 presents the spectrum of radiation of the overvoltage nanosecond discharge between chalcopyrite electrodes at the argon pressure of $202 \mathrm{kPa}$. Table 1 shows the results of decoding the most intense spectral lines and molecular bands and their relative radiation intensities, which correspond to Figure 3. The discharge radiation spectrum consisted of the group of intense spectral lines of the copper atom and the single charged indium ion in the spectral range of 200-230 nm. A similar phenomenon was observed in the plasma of the over-voltage nanosecond discharge at the atmospheric pressure and the distance between copper electrodes $\mathrm{d}=2 \mathrm{~mm}[15,16]$ (in the part of atoms and single charged copper ions). As the argon pressure increased from 101 to $202 \mathrm{kPa}$, the intensity of the spectral lines of 218.17 and $219.95 \mathrm{~nm}$ of the copper atom decreased. This is probably due to an increase of UV radiation absorption and an increase in the concentration of chalcopyrite vapor or its decay products in the discharge plasma, since the pulse energy contribution to the plasma increases.

The intensities of the ion spectral lines of indium increased with increasing argon pressure from 101 to $202 \mathrm{kPa}$ and, accordingly, with increasing energy contribution to the discharge. Also, intensities of copper ion lines for the overvoltage nanosecond discharge in air of the atmospheric pressure between copper electrodes were increased.

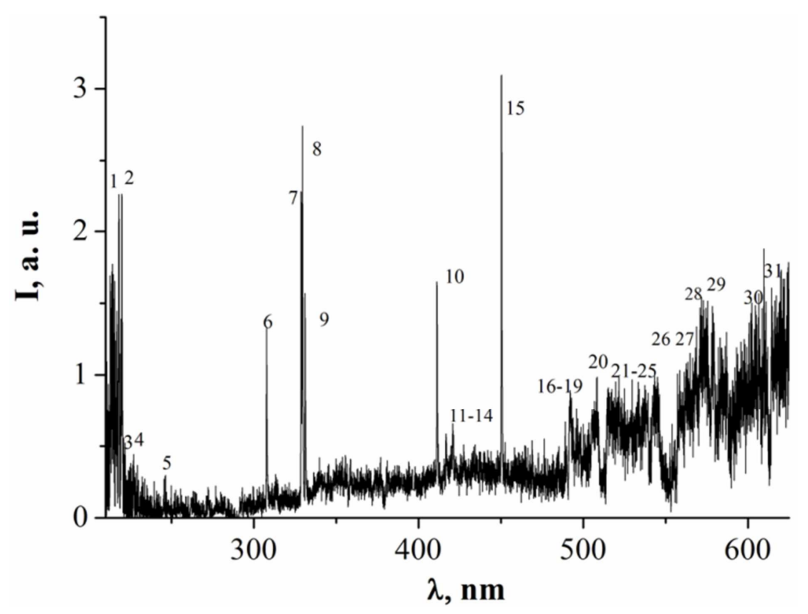

Figure 3. Radiation spectrum of over-voltage nanosecond discharge between chalcopyrite electrodes at argon pressure of $202 \mathrm{kPa}$.

Table 1. Results of identification of the most intensive spectral lines and bands of decay products of chalcopyrite molecule in over-voltage nanosecond discharge at $p(A r)=202 \mathrm{kPa}$.

\begin{tabular}{|c|c|c|c|c|c|c|c|}
\hline № & $\lambda . \mathbf{n m}$ & I, a. u. (at p (Ar) $=202 \mathrm{kPa})$ & Object & $E_{\text {low., }}, \mathrm{eV}$ & $\mathbf{E}_{\text {up. }}, \mathrm{eV}$ & Lower level & Upper level \\
\hline 1 & 218.17 & 0.33 & $\mathrm{Cu} \mathrm{I}$ & 0.00 & 5.68 & $4 s^{2} S$ & $4 p^{\prime 2} \mathrm{P}^{0}$ \\
\hline 2 & 219.95 & 0.37 & $\mathrm{Cu} \mathrm{I}$ & 1.39 & 7.02 & $4 s^{22} \mathrm{D}$ & $4 p^{\prime \prime 2} D^{\circ}$ \\
\hline 3 & 225.57 & 1.66 & In II & 12.68 & 18.17 & $5 s 5 d^{3} D_{3}$ & $5 s 4 f^{3} F^{o}$ \\
\hline 4 & 226.37 & 1.64 & $\mathrm{Cu} \mathrm{II}$ & 8.92 & 14.39 & $4 p^{\prime 1} F^{o}$ & $4 d^{3} G$ \\
\hline 5 & 246.02 & 0.41 & In II & 12.68 & 17.72 & $5 s 5 d 3 D$ & $5 s 7 f^{3} \mathrm{~F}^{\circ}$ \\
\hline 6 & 307.38 & 1.70 & $\mathrm{Cu} \mathrm{I}$ & 1.39 & 5.42 & $4 s^{22} \mathrm{D}$ & $4 p^{\prime} 2 F^{o}$ \\
\hline 7 & 328.27 & 2.35 & $\mathrm{Cu} \mathrm{I}$ & 5.15 & 8.93 & $4 p^{\prime 4} F^{o}$ & $4 d^{\prime 2} G$ \\
\hline 9 & 330.79 & 1.76 & $\mathrm{Cu} \mathrm{I}$ & 5.07 & 8.82 & $4 p^{\prime 4} F^{o}$ & $4 d^{\prime}{ }^{4} G$ \\
\hline 10 & 410.17 & 1.75 & In I & - & 3.02 & $5 \mathrm{~s}^{2} 5 \mathrm{p}^{2} \mathrm{P}^{\mathrm{o}}$ & $5 \mathrm{~s}^{2} 6 \mathrm{~s}^{2} \mathrm{~S}_{1 / 2}$ \\
\hline 11 & 417.83 & 0.73 & Ar II & 16.64 & 19.61 & $4 s^{4} \mathrm{P}$ & $4 p^{4} D^{0}$ \\
\hline 12 & 422.26 & 0.85 & Ar II & 19.87 & 22.80 & $4 p^{2} P^{o}$ & $5 \mathrm{~s}^{2} \mathrm{P}$ \\
\hline 13 & 427.75 & 0.7 & Ar II & 18.45 & 21.35 & $4 s^{\prime 2} D$ & $4 p^{\prime 2} P^{o}$ \\
\hline 14 & 436.20 & 0.95 & Ar II & 18.66 & 21.50 & $3 d^{2} \mathrm{D}$ & $4 p^{\prime 2} D^{\circ}$ \\
\hline 15 & 451.13 & 3.27 & In I & 0.27 & 3.02 & $5 s^{2} 5 p^{2} P^{o}$ & $5 s^{2} 6 s^{2} S_{112}$ \\
\hline 18 & 502.82 & 0.75 & $\mathrm{Cu}$ II & 14.43 & 16.87 & $4 d^{3} D$ & $4 f^{3} F^{0}$ \\
\hline 19 & 506.06 & 0.8 & $\mathrm{Cu}$ II & 8.54 & 10.99 & $4 p^{3} P^{o}$ & $4 s^{23} \mathrm{P}$ \\
\hline 20 & 507.22 & 0.63 & $\mathrm{Cu}$ II & 14.42 & 16.87 & $4 d^{3} F$ & $4 f^{3} F^{o}$ \\
\hline 21 & 510.00 & 0.52 & $\mathrm{Cu}$ II & 14.43 & 16.86 & $4 d^{3} D$ & $4 f^{3} D^{o}$ \\
\hline 22 & 515.32 & 0.7 & $\mathrm{Cu} \mathrm{I}$ & 3.79 & 6.19 & $4 p^{2} \mathrm{P}^{o}$ & $4 d^{2} D$ \\
\hline 23 & 520.09 & 0.76 & $\mathrm{Cu} \mathrm{I}$ & 5.42 & 7.80 & $4 p^{\prime}{ }^{2} F^{o}$ & $5 s^{\prime 4} D$ \\
\hline 24 & 521.82 & 0.87 & $\mathrm{Cu} \mathrm{I}$ & 3.82 & 6.19 & $4 p^{2} P^{o}$ & $4 d^{2} D$ \\
\hline 25 & 522.00 & 0.85 & $\mathrm{Cu} \mathrm{I}$ & 3.82 & 6.19 & $4 p^{2} P^{o}$ & $4 d^{2} D$ \\
\hline 26 & 556.69 & 1.21 & Se II & & & & \\
\hline 27 & 557.69 & 0.90 & In II & 15.81 & 18.03 & $5 \mathrm{~s} 7 \mathrm{p}^{1} \mathrm{P}^{\mathrm{o}}$ & $5 \mathrm{~s} 10 \mathrm{~d}^{3} \mathrm{D}$ \\
\hline 28 & 570.02 & 0.67 & $\mathrm{Cu} \mathrm{I}$ & 1.64 & 3.82 & $4 s^{22} \mathrm{D}$ & $4 p^{2} \mathrm{P}^{o}$ \\
\hline 29 & 572.18 & 1.15 & In II & 15.29 & 17.46 & $5 s 7 s{ }^{1} \mathrm{~S}$ & $5 s 9 p{ }^{1} \mathrm{P}^{\circ}$ \\
\hline 30 & 594.92 & 1.10 & Ar I & 13.28 & 15.35 & $4 p^{\prime}\left[\begin{array}{ll}1 & 1 / 2\end{array}\right]$ & $6 \mathrm{~d}\left[\begin{array}{ll}1 & 1 / 2\end{array}\right]$ \\
\hline 31 & 622.42 & 2.20 & In II & 15.77 & 17.76 & $5 s 7 p^{3} \mathrm{P}^{\circ}$ & $5 s 9 d^{3} \mathrm{D}$ \\
\hline
\end{tabular}


Another group of intense spectral lines (lines 6-15, Table) was observed against the background of the continuous radiation intensity. The continuum intensity increased slightly with the wavelength increasing (Figure 3). The intensities of these spectral lines of copper and indium atoms as well as single-charged argon ions increased with increasing argon pressure and pulsed energy contribution to the plasma. The radiation in the spectral range of 460-630 $\mathrm{nm}$ was in the form of molecular bands, on the background of which some low-intensity spectral lines of atoms and ions were observed.

An accurate identification of these lines requires the use of a higher spectral resolution spectrophotometer. Most likely, the emission spectrum of the discharge plasma in this case is related to the emission of selenium molecules, as well as atoms and ions of argon. The following intense spectral lines of copper and indium atoms in the spectral range of 300-460 $\mathrm{nm}$ can be used to diagnose the process of depositing chalcopyrite thin films on solid glass or quartz substrates: $307.38 \mathrm{CuI}, 329.05 \mathrm{Cu}$ I, 410.17 In I and 451.13 nm I.

\section{Transmission Spectra of Films}

Typical transmission spectra of the deuterium lamp radiation in the spectral region of 200-500 nm of chalcopyrite film samples, which were synthesized in our experiments at various argon pressures, are shown in Figure 4. The transmission of chalcopyrite films compared to the transmission of the substrate decreased by 2-3 times and was minimal for argon-based mixtures at $\mathrm{p}(\mathrm{Ar})=101 \mathrm{kPa}$. Transmission spectra shapes of chalcopyrite films at argon pressures of 13.3 and $101 \mathrm{kPa}$ were the same.

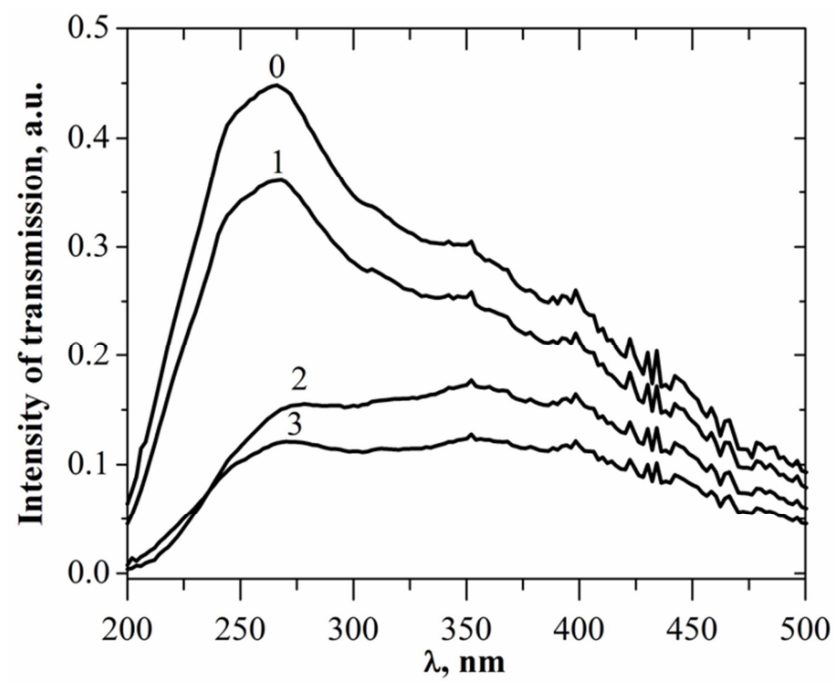

Figure 4. Transmission spectra of samples of chalcopyrite films deposited on quartz substrates depending on the pressure and type of gas environment: 0 - without sample; 1 - pure quartz glass; 2 - CuInSe $e_{2}$ electrodes at $p$ $(\mathrm{Ar})=13.3 \mathrm{kPa} ; 3-\mathrm{CuInSe}_{2}$ at $\mathrm{p}(\mathrm{Ar})=101 \mathrm{kPa}$.

The strong absorption of deuterium lamp radiation by chalcopyrite films in the spectral region of 200-500 $\mathrm{nm}$ is due to the fact that when the chalcopyrite films are deposited with gas-discharge method, they repeat the stoichiometry of the electrode material.

\section{Conclusions}

Thus, it was found that at the pressure of argon equal to $202 \mathrm{kPa}$ between electrodes based on the CuInSe 2 compound and at $1 \mathrm{~mm}$ interelectrode distance, the homogeneous nanosecond discharge with the pulsed electrical power of 7$10.5 \mathrm{MW}$ and the energy contribution to the plasma of 0.35 $0,44 \mathrm{~J}$ is ignited. The investigation of spectral characteristics of the plasma based on $\mathrm{Ar}-\mathrm{CuInSe} \mathrm{C}_{2}$ vapor-gas mixtures showed that the most intensive are the spectral lines of the copper atom in the range of 200-250 $\mathrm{nm}$ and the spectral lines of the indium atom and the copper and indium ions in the longer-wavelength region of the spectrum.

The features of the plasma emission spectra allows to suggest the presence of selective mechanisms for the formation of excited atoms and ions of copper and indium in the plasma, which are determined by the transfer of energy from metastable atoms and argon molecules to chalcopyrite molecules. Based on the measured relative intensities of the spectral lines of copper and indium atoms and ions, it is possible to estimate the temperature and electron density of the studied plasma. The following separately positioned and most intensive lines in the spectral range of 300-460 nm can be used to diagnose the chalcopyrite film sputtering: 307.38 CuI, 329.05 Cu I, 410.17 In I, 451.13 nm In I.

Investigation of the transmission spectra of probing radiation in the spectral range of 200-800 $\mathrm{nm}$ by chalcopyrite films deposited by the pulsed gas discharge method showed that the smallest transmittance is characteristic of films that were synthesized at argon atmospheric pressure.

\section{References}

[1] M. P. Chuchman, G. E. Laslov, A. K. Shuaibov, L. L. Shimon. Emission charachteristics and parameters of CuInSe2 laser torch plasma//Ukr. J. Phys. 2012. Vol. 57, №.1. P. 23-29.

[2] M. P. Chuchman, G. E. Laslov, A. K. Shuaibov. Radiation Dynamics of Low-Energy Laser Plasma of CuSbSe2 Polycrstalline//High Temperature. 2014. Vol. 52, №4. P. 497 500 .

[3] Alekander K. Shuaibov, Alekander Y. Minya, Mikaylo P. Chuchman, Antonina A. Malinina, Alekander N. Malinin, T. Zoltan Gomoki and Yanosh Ch. Kolozvari. Optical Charachteristics of overstressed nanosecond discharge in atmospheric pressure air between Chalcopyrite electrodes//Plasma Research Express. 2018. №1. 015003 (10 pp).

[4] O. K. Shuaibov, A. O. Malinina, O. M. Malinin. New gas discharge methods for the production of selective ultraviolet and visible radiation and synthesis of nanostructures of transition metal oxides. Monograph. Uzhhorod. Publishing House of UzhNU "Hoverla", 2019. 188 p. 
[5] E. Kh. Bakst, V. F. Tarasenko, Yu. V. Shutko, M. V. Erofeev. A point source of UV radiation with a frequency of $1 \mathrm{kHz}$ and a short pulse duration//News of higher educational institutions. Physics. 2011. No. 11. P. 91-94.

[6] E. Kh. Baksht, V. F. Tarasenko, Yu. V. Shut' ko, V. V. Erifeev. Point-like pulse-periodic UV radiation source wich a short duration//Quantum Electronics. 2012. Vol. 42, N 2. P. 153156.

[7] Holovey V. M., Popovych K. P., Prymak M. V., Birov M. M., KrasilinetsV. M., Sidey V. I. X-ray induced optical absorption in Li2B4O7 and Li2B4O7: $\mathrm{Cu}$ single crystals and glasses.//Physica B. 2014. V. 450. P. 34-38.

[8] S. V. Avtaeva, O. S. Zhdanov, A. A. Pikulev, E. A. Sosnin, V. F. Tarasenko. New directions in scientific research and applications of excilamps. Monograph//2013. Tomsk. STT. $240 \mathrm{~s}$.

[9] V. Yu. Kozhevnikov, A. V. Kozyrev, N. M. Dmitrieva. Theoretical 0-D modeling of a subnanosecond high-pressure gas discharge//News of Higher Educational Establishments. Physics. 2014. V. 57, No. 3/2. S. 130-133.

[10] R. V. Hrytsak, A. O. Malinina, O. J. Minya, O. K. Shuaibov, S. Y. Neymet. Characteristics of Overstressed Nanosecond Discharge between Electrodes from Chalcopirite in Argon of Atmospheric Pressure//XIX International Young Scientists Conference on Applied Physics. 21-25 May. 2019. Kyiv. Taras Shevchenko National University. Programme and Abstracts. P. 37-38.
[11] I. E. Kacher, A. K. Shuaibov, M. Yu. Regan, A. I. Dashchenko. Optical diagnostics of laser evaporation of polycrystalline compound CuInS2//Thermophysics of high temperatures. 2002, V. 40, No 6, p. 880-883.

[12] O. K. Shuaibov, M. P. Chuchman, L. L. Shimon, I. E. Kacher. Investigation of optical characteristics and parameters of laser plasma of CuInS2 polycrystalline charge and its components//Ukrainian Physical Journal. 2003. Vol. 48, No. 3, P. 223-231.

[13] A. K. Shuaibov, M. P. Chuchman, A. I. Dashchenko. Investigation of the dynamics of radiation of an erosive laser plasma of a CuInS2 polycrystal//Letters in ZhTF. 2003. V. 29. issue 10. S. 23-28.

[14] Laslov Geza, Shuaibov Alexander, Szegeli Sandor and Laszlo Elemer. Spectroscopic Diagnostics of Sparc Discharge Plasma at Atmocpheric Pressure//J. Chem. Eng. 2014. V. 8. P. $302-$ 305 .

[15] A. K. Shuaibov, A. Y. Minya, A. A. Malinina, A. N. Malinin, V. V. Danilo, M. Yu. Sichka, I. V. Shevera. Synthesis of Copper Oxides Nanostructures by an Overstressed Nanosecond Discharge in Atmospheric Pressure Air Between Copper Electrodes//Amerikan Journal of Mechanical and Materials Engineering. 2018; 2 (1), p. 8-14.

[16] O. K. Shuaibov, A. I. Minya, Z. T. Gomoki, and V. V. Danilo, and P. V. Pinzenik. Charachterristics of a High-Current Pulse Discharge in Air wich Ectonic Mechanism of Copper Vapor Injection into Disharge//Surface Engineering and Applied Electrochemistry. 2019. Vol. 55, №1, pp. 65-90. 